\title{
ANALISIS PENYEBAB KEGAGALAN PEMBAKARAN PADA BURNER BOILER DI ATAS KAPAL
}

\author{
Victoria Handiyan $^{\mathrm{a}}$, Febria Surjaman ${ }^{\mathrm{b}}$ dan Sri Purwantini ${ }^{\mathrm{c}}$ \\ ${ }^{a}$ Taruna (NIT.49124674.T) Program Studi Teknika PIP Semarang \\ ${ }^{\mathrm{b}}$ Dosen Program Studi Teknika PIP Semarang \\ ${ }^{c}$ Dosen Program Studi KALK PIP Semarang
}

\begin{abstract}
ABSTRAK
Auxilary Boiler (ketel uap bantu) merupakan mesin yang digunakan untuk memproduksi uap bertekanan yang sangat dibutuhkan di kapal, diantaranya untuk pemanas bahan bakar, minyak lumas, dan pemanas air untuk akomodasi maupun permesinan. Jenis dari ketel uap ini ada dua yaitu ketel pipa air dan ketel pipa api. Pada kapal MV. Ultra Cory menggunakan jenis pipa air. Boiler agar bekerja secara optimal harus didukung oleh beberapa faktor, diantaranya yang paling penting adalah faktor pembakaran. Burner merupakan komponen utama dalam pembakaran sering mengalami masalah. Maka dari itu perlu diketahui hal apa saja yang menjadi penyebab kegagalan penyalaan Burner tersebut. Dalam hal ini penulis menggunakan metode AHP(Analytical Hierarchy Process), dimana metode ini untuk menentukan faktor penyebab kegagalan pembakaran pada Burner boiler, yang mana dalam menentukan masalah tersebut akan dicari dengan menentukan nilai tertinggi dari penghitungan matriknya dan nilai eigennya. Pada AHP ini dalam mencari nilai tertinggi akan dibagi dengan beberapa sub bagian, yaitu kriteria dan alternatif. Untuk sub kriteria diambil faktor penyetelan, kondisi komponen dan perawatan komponen. Sedangkan untuk sub alternatif diambil dari komponen Burner dan pendukungnya, ignition rod, elektroda, nozzle tip, nozzle pipe dan flame eye.Daris hasil analisis tersebut didapatkan bahwa penyebab utama kegagalan pembakaran pada Burner yaitu dari faktor penyetelan pada Burner. Upaya yang dilakuakan agar ketel uap bekerja secara maksimal yaitu dengan melakukan perawatan, pengecekan, dan perbaikan sesuai dengan standar yang sudah ditentukan oleh manual book terutama dalam faktor pembakaran.
\end{abstract}

\section{Kata kunci : auxiliary boiler, analytical hierarchy process, burner}

\section{PENDAHULUAN}

Banyak kapal sekarang yang dilengkapi dengan pesawat bantu berupa ketel uap. Auxilliary Boiler (ketel bantu) adalah sebuah bejana tertutup yang dapat menghasilkan uap dengan tekanan lebih dari 1 atmosfer, dimana uap yang didapatkan merupakan proses pemanasan dari air tawar. Air tawar yang dipanaskan bisa berada di dalam pipa (water tube type) maupun di luar pipa (fire tube type), tergantung dari tipe tiap boiler. Dan uap yang dihasilkan dari boiler tersebut digunakan untuk mencukupi kebutuhan pemanasan minyak lumas, pemanasan bahan bakar, pemanas air untuk akomodasi dan kebutuhan uap pemanas lain, baik di engine room, dek maupun galley. Untuk mencukupi kebutuhan uap bertekanan tersebut, mengingat pentingnya fungsi uap bertekanan tersebut untuk menunjang operasional kapal, uap bertekanan tersebut hanya dapat dicapai apabila pesawat bantu ketel uap bekerja dengan baik dan normal oleh karena itu diperlukan pemahaman terhadap pesawat bantu ketel khususnya pada komponen utama yang mudah kotor, rusak, dan bocor, yang nantinya akan mengganggu kinerja pada ketel uap dalam proses pembentukan uap. Agar ketel bantu ini selalu dalam keadaan baik untuk beroperasi maka kita harus selalu merawat pesawat ini secara periodik, sesuai dengan jam kerja atau yang ditentukan oleh buku 
manual dari pabrik pembuatannya. Perawatan yang biasanya dilakukan pada ketel uap meliputi perawatan pada alat pembakaran (burner), perawatan pada air pengisian ketel, perawatan pada bahan bakar, perawatan forced draft fan, instalasi kelistrikan dan kain sebagainya. Apabila seluruh komponen tersebut dirawat sesuai dengan prosedur maka akan sangat mempengaruhi kinerja pada ketel uap, mengurangi jumlah kerusakan pada komponen dan menjamin kelancaran permesinan yang membutuhkan uap. Namun kenyataan yang ada di atas kapal, masih terjadi beberapa masalah dalam operasional ketel uap. Diantaranya pada saat kapal pada saat kapal sedang anchorage di Taboneo, Banjarmasin, Kalimantan Selatan tanggal 13 maret 2015, pada saat olah gerak selesai penulis dan Masinis 3 menyiapkan boiler untuk dinyalakan, setelah boiler berhasil dinyalakan penulis dan Masinis 3 kembali ke engine control room. Beberapa saat kemudian terjadi alarm di kamar mesin, setelah dilihat di monitor, alarm disebabkan karena Auxilliary Boiler miss fire. Penulis dan Masinis 3 pun melakukan pengecekan terhadap boiler, setelah dilakukan penegecekan, faktor penyebab kegagalan penyalaan pada burner. Kemudian Masinis 3 dan penulis membongkar burner tersebut, dan didapati terdapat kerak nozzle tip burner, jarak elektroda yang merenggang, melakukuan pembersihan, penyetelan dan pengecekan komponen burner set tersebut. Setelah semua selesai dalam perawatan, Masinis 3 dan penulis memasang kembali burner pada boiler, menyalakannya kembali dan boiler bekerja secara normal. Namun 2 hari kemudian terjadi alarm lagi yang disebabkan miss fire pada boiler, kemudian masinis 3 dan penulis melakukan pengecekan pada boiler dan didapati masalah yang sama, yaitu pada burner. Kemudian masinis 3 dan penulis membongkar burner set dan melakukan pengecekan, pembersihan dan penyetelan. Saat melakukan pengecekan pada elektroda didapati jarak antara elektroda dengan atomizer tidak sesuai standar pada instruction manual book.

Dari beberapa faktor penyebab kerusakan pada ketel uap, baik dari hasil pengamatan langsung, keterangan data dari logbook dan wawancara secara langsung dengan Masinis 3 yang bertanggung jawab terhadap permesinan ketel uap tersebut. Data akan akan diolah dengan menggunakan metode Analytical Hierarchy Process (AHP) untuk menemukan faktor penyebab yang sering timbul dalam pengoperasian ketel uap.

\section{Waktu dan Tempat Penelitian}

Penelitian dilaksanakan di atas kapal MV. ULTRA CORY, yang dimiliki oleh perusahaan World Marine Co.,Ltd, Imabari Japan. Kapal ini berjenis kapal curah (Bulk Carrier) yang memiliki kapasitas angkut 77,674.69 M3, dibuat pada tanggal 16 Desember tahun 2010, oleh SHIN KASADO DOCKYARD Co., Ltd, Japan, \#S-K045. Kapal berbendera Panama, DWT 34,794 ton, LOA 199,98 meter, LBP 195 meter, dengan operator SMTECH SHIP MANAGEMENT CO.,Ltd, Main Engine HITACHI-MAN B\&W 6S50ME- C, (MK 8) x 1SET, 8,450 Kw x 108 RPM (MAX), $7,185 \times 102$ RPM (85\% M.C.R) 14.5 Kts (NOR with $15 \%$ S.M)

Rute pelayaran kapal memiliki route liner, yang berarti pelayaran yang tetap. Penelitian dilakukan secara langsung pada saat kapal maneuver dari Geelong Port, Melbourne, Australiamen ujung pelabuhan Tiajin, China. Peneliti berusaha mencari dan mengumpulkan data nyata dari lapangan yang kemudian diolah menjadi bahan penelitian. Waktu penelitian dilakukan selama dua belas bulan 10 hari ketika Penulis melakukan Praktek Laut, yaitu terhitung mulai tanggal 31 Oktober 2014 sampai dengan 12 Desember 2015.

\section{METODE PENELITIAN}

Data yang didapat dari hasil penelitian yang mencakup pengamatan, wawancara, dan dokumentasi yaitu dalam bentuk kata- 
kata, termasuk kutipan-kutipan atau deskripsi peristiwa-peristiwa khusus mengenai objek penelitian. Dalam hal ini untuk mengkaji hasil penelitian, Penulis menggunakan metode penelitian kualitatif dan data yang digunakan yaitu dalam bentuk teks, kata-kata tertulis, frase-frase atau simbol yang mendeskripsikan atau mepresentasikan tindakan-tindakan, dan peristiwa-peristiwa yang terjadi dalam objek penelitian.

Prosedur analisis penelitian kualitatif mengacu pada prosedur analisis non matematis yang hasil temuannya diperoleh dari data yang dihimpun oleh ragam alat. Alat yang digunakan sebagai teknik analisis dalam penelitian ini yaitu Analytical Hierarchy Process. Proses Hierarki Analitik (Analytical Hierarchy Process - AHP).

Dikembangkan oleh Thomas L. Saaty dari Whartoon School of Business pada tahun 1970-an untuk mengorganisasikan informasi dan judgment dalam memilih alternatif yang paling disukai. Dengan menggunakan AHP, suatu persoalan yang akan dipecahkan dalam suatu kerangka berpikir yang terorganisir, sehingga memungkinkan dapat diekspresikan untuk mengambil keputusan yang efektif atas persoalan tersebut.

Persoalan yang kompleks dapat disederhanakan dan dipercepat proses pengambilan keputusannya. Prinsip kerja AHP adalah penyederhanaan suatu persoalan kompleks yang tidak terstruktur, stratejik dan dinamik menjadi bagianbagiannya, serta menata dalam suatu hierarki. Kemudian tingkat kepentingan setiap variabel diberi nilai numerik secara subjektif tentang arti penting variabel tersebut secara relatif dibandingkan dengan variabel yang lain. Dari berbagai pertimbangan tersebut kemudian dilakukan sintesa untuk menetapkan variabel yang memiliki prioritas tinggi dan berperan untuk mempengaruhi hasil pada sistem tersebut. Secara grafis, persoalan keputusan AHP dapat dikonstruksikan sebagai diagram bertingkat, yang dimulai dengan sasaran, lalu kriteria level pertama, subkriteria dan akhirnya alternatif. AHP memungkinkan pengguna untuk memberikan nilai bobot relatif dari suatu kriteria majemuk (atau alternatif majemuk terhadap suatu kriteria) secara intuitif, yaitu dengan melakukan perbandingan berpasangan (pairwise comparisons).

\section{HASIL PENELITIAN DAN DISKUSI}

Dalam menentukan faktor penyebab kegagalan pembakaran pada burner, penulis menganalisis faktor tersebut dengan menggunakan metode Analytical Hierarchy Process. Sebelum menentukan faktor permasalahan utama yang mengakibatkan kegagalan pembakaran burner, penulis menganalisa penyebab yang mungkin terjadi pada ketel uap selama penulis melakukan pengamatan. Pertama yang dilakukan yaitu membuat kerangka diagram AHP. Secara grafis, persoalan keputusan AHP dapat di konstruksikan sebagai diagram bertingkat, yang dimulai dengan sasaran, lalu kriteria level pertama, subkriteria dan akhirnya alternatif. AHP memungkinkan pengguna untuk memberikan nilai bobot relatif dari suatu kriteria majemuk (atau alternatif majemuk terhadap suatu kriteria) secara intuitif, yaitu dengan melakukan perbandingan berpasangan (pairwise comparisons).

Berdasarkan hasil analisis dan pengamatan yang telah dilakukan, kegagalan pembakaran pada burner dipengaruhi oleh faktor penyetelan burner, yang mana dalam hal ini adalah penyetelan antara dua katup elektroda dan nozzle tip pada burner yang tidak sesuai dengan manual book. Untuk menyelesaikan masalah tersebut, maka perlu dilakukan tiga langkah berikut: Penentuan sasaran yang ingin dicapai: kegagalan penyalaan burner, Penentuan kriteria pemilihan (penyetelan, perawatan komponen, kondisi komponen). Penentuan alternatif pilihan (ignition rod, elektroda, nozzle tip, nozzle pipe, flame eye). Setelah mengetahui langkah awal penyelesaian masalah tersebut, maka dibuat diagram dari 
masalah tersebut (gambar 5). Kemudian lakukan Penyelesaian dengan manipulasi matriks. Matrik akan diolah untuk menentukan bobot dari kriteria, yaitu dengan jalan menentukan nilai eigen (eigenvector). Prosedur untuk mendapatkan nilai eigen adalah Kuadratkan matriks tersebut, hitung jumlah nilai dari setiap baris, kemudian lakukan normalisasi, hentikan proses ini, bila perbedaan antara jumlah dari dua perhitungan berturut-turut lebih kecil dari suatu nilai batas tertentu. Lakukan penghitungan pada setiap bagian (langkah perhitungan di lampiran), langkah pertama yaitu manenntukan nilai kriteria, cari nilai bobot tiap kriteria (tabel 1), kemudian lakukan perhitungan matriks pada kriteria penyetelan, kondisi komponen dan perawatan komponen seperti langkah di atas.

Setelah didapat masing-masing nilai eigennya maka dapat diketahui nilai terbesar yang merupakan faktor utama, kemudian buat diagram untuk nilai kriteria (gambar 6). Langkah kedua yaitu menentukan nilai alternatif, cari nilai bobot tiap alternatif (tabel 2), lakukan penghitungan matrik pada masing-masing alternatif, ignition, elektroda, nozzle tip, nozzle pipe dan flame eye seperti langkah di atas, setelah didapat nilai eigennya maka dapat diketahui nilai terbesar yang merupakan faktor utama. Kemudian buat tabel hasil semua nilai eigennya (tabel 3), buat diagram nilai alternatif (gambar 7), dan buat diagram hasil seluruh bobot dengan nilai eigennya (gambar 8). Maka dapat diketahui bahwa faktor utama penyebab kegagalan pembakaran pada burner yaitu pada faktor penyetelan elektroda.

\section{KESIMPULAN}

Faktor penyebab kegagalan pembakaran pada burner yaitu pada penyetelan elektroda, jarak antara elektroda sangat berpengaruh dalam menghasilkan percikan api yang nantinya digunakan sebagai pematik dalam pembakaran di ketel uap. Kurangnya ketelitian dalam pengukuran dan kurangnya perhatian dalam mengikuti prosedur dalam manual book dapat menjadi faktor penyebab kegagalan pembakaran pada Burner.

\section{DAFTAR PUSTAKA}

Agustinova, Danu Eko. 2015. Memahami Metode Penelitian Kualitatif Teori dan Praktik. Yogyakarta: Calpulis

Djokosetyardjo, M J. 2003. Ketel Uap. Jakarta: PT Pradnya Paramitra

Husein, Umar. 2003. Metode Riset Perilaku Konsumen Jasa. Jakarta: Ghalia Indonesia

Instruction manual book of Auxilliary Boiler MIURA GK-2028

Murni. 2012. Buku Ajar Ketel Uap. Semarang: UPT UNDIP Press

Marimin. 2004. Teknik dan Aplikasi Pengambilan Keputusan Kriteria Majemuk. Jakarta: PT Grasindo 


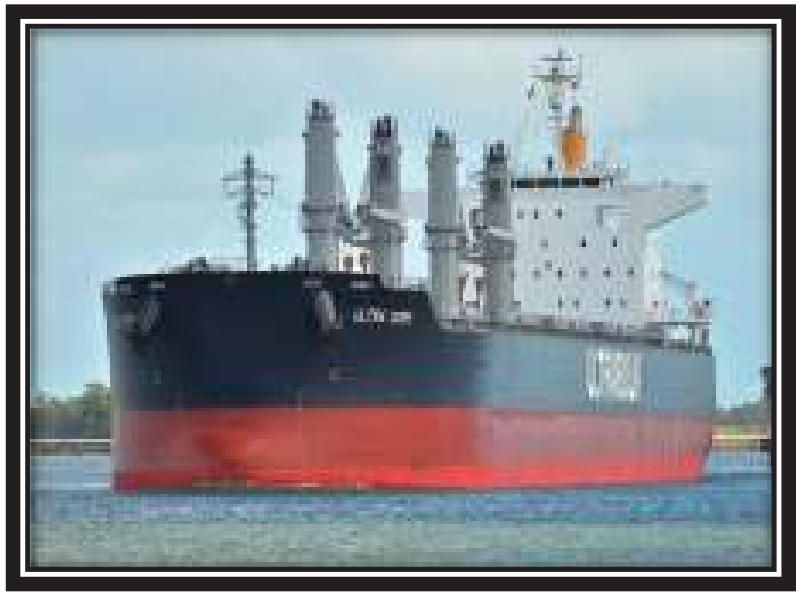

Gambar 1 : Lokasi Penelitian

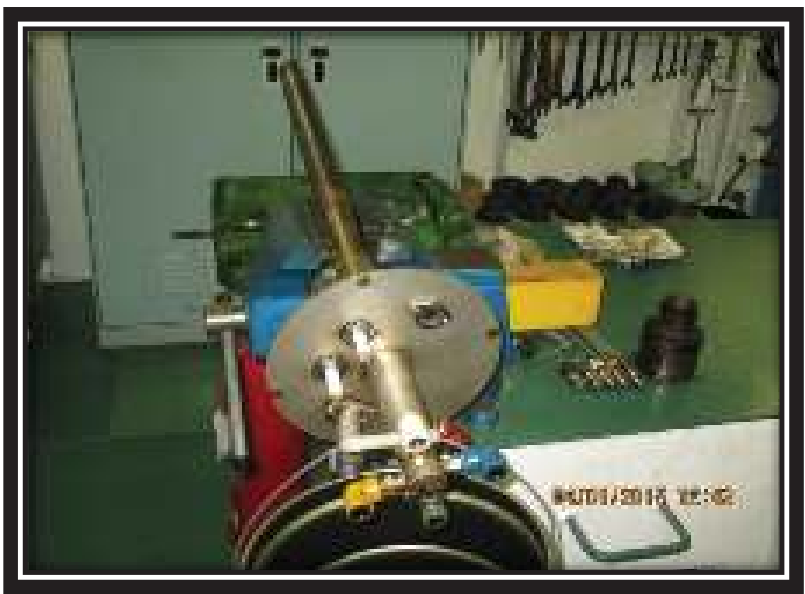

Gambar 3 : Pembersihan komponen burner

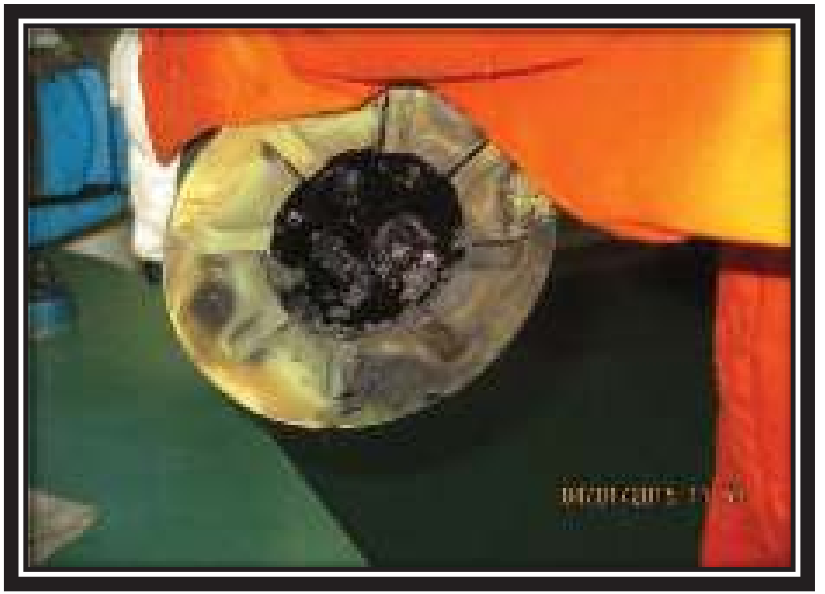

Gambar 2 : Kerak pada nozzle tip

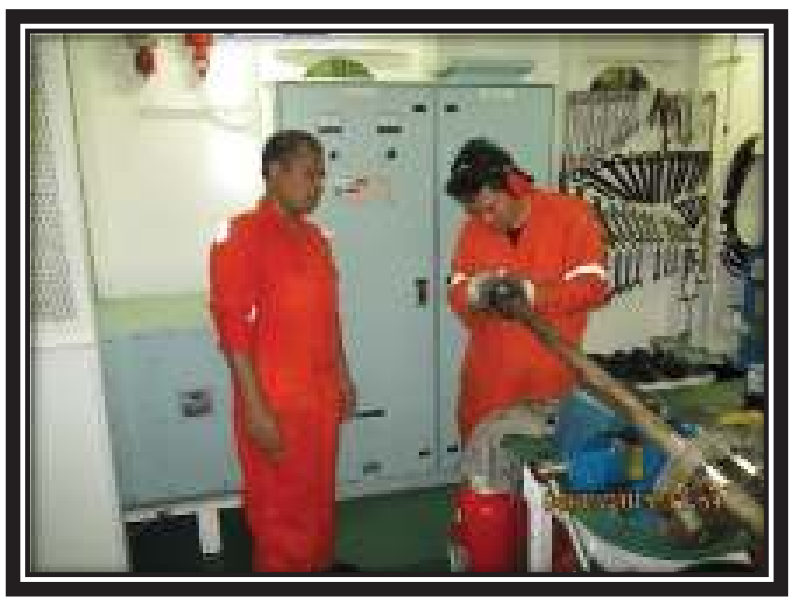

Gambar 4 : Clearance pada elektroda 


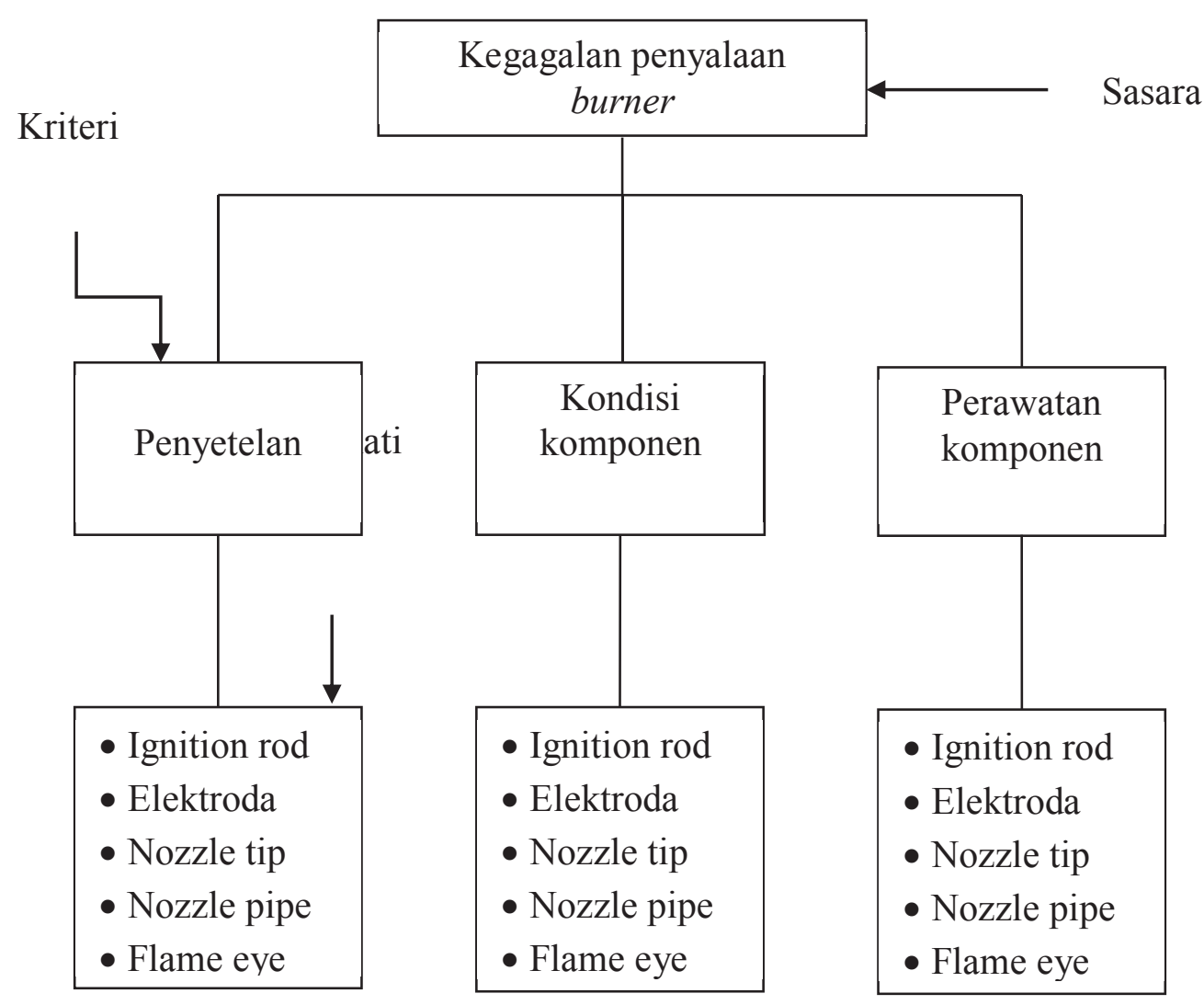

Gambar 5 : Diagram AHP

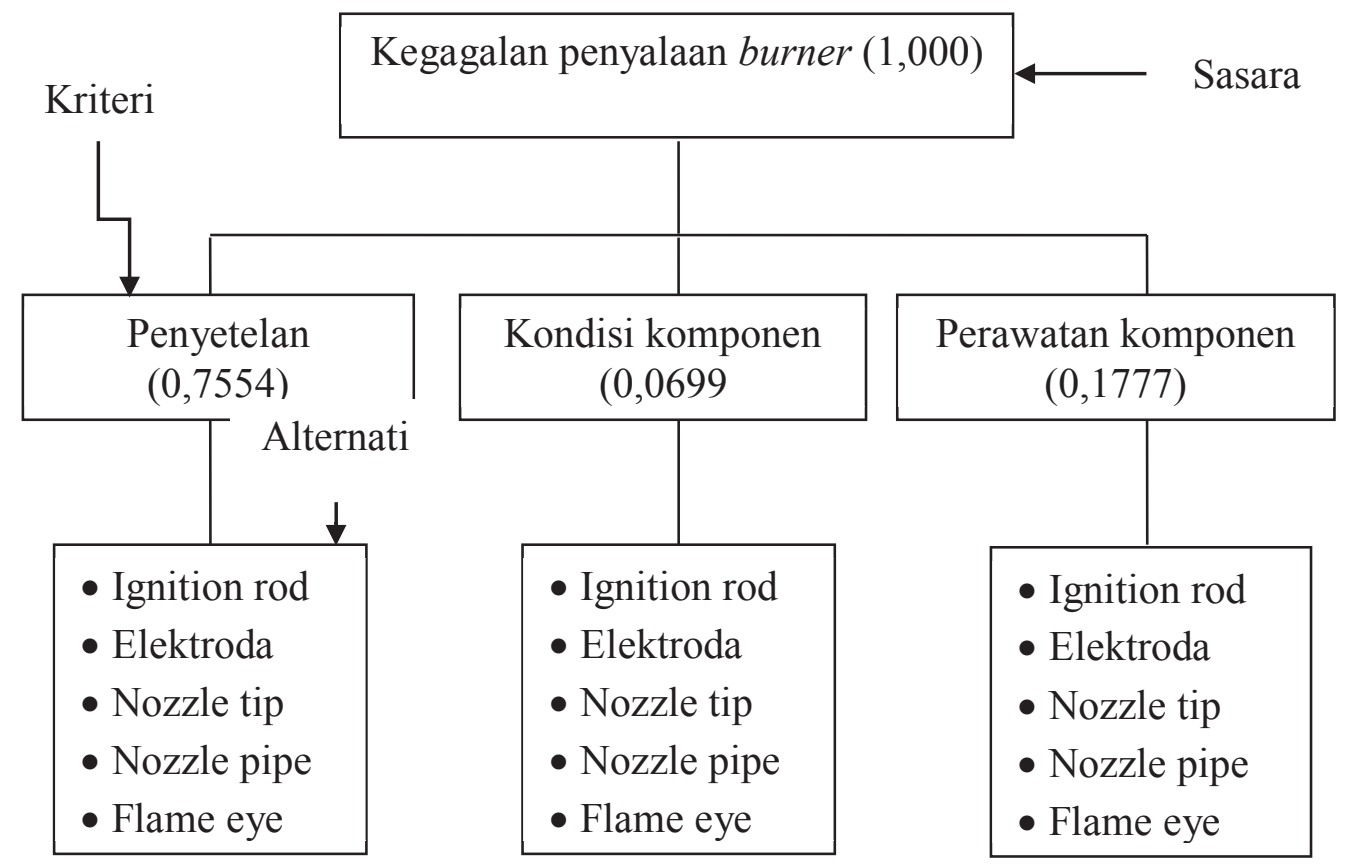

Gambar 6 : Hasil bobot kriteria 


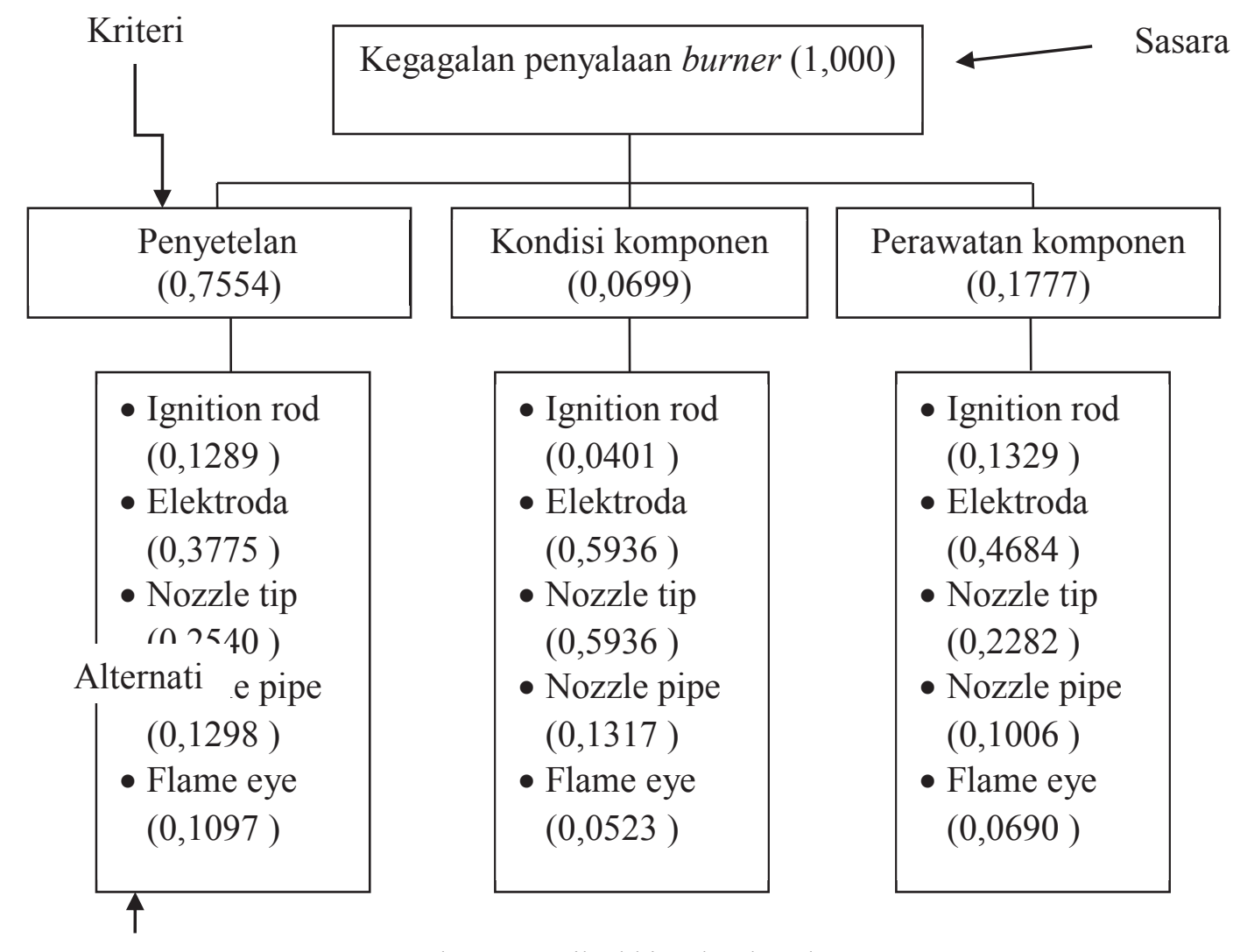

Gambar 7 : Hasil Akhir seluruh Bobot

Tabel 1 : Nilai bobot kriteria

\begin{tabular}{|c|c|c|c|c|c|c|c|c|c|c|c|c|c|c|c|c|c|c|}
\hline Kriteria & \multicolumn{10}{|c|}{ kobot tingkat kepentingan berpasangan } & kriteria \\
\hline Penyetelan & 9 & 8 & 7 & 6 & 5 & 4 & 3 & 2 & 1 & 2 & 3 & 4 & 5 & 6 & 7 & 8 & 9 & $\begin{array}{c}\text { Kondisi } \\
\text { komponen }\end{array}$ \\
\hline Penyetelan & 9 & 8 & 7 & 6 & 5 & 4 & 3 & 2 & 1 & 2 & 3 & 4 & 5 & 6 & 7 & 8 & 9 & $\begin{array}{c}\text { Perawatan } \\
\text { komponen }\end{array}$ \\
\hline $\begin{array}{c}\text { Kondisi } \\
\text { komponen }\end{array}$ & 9 & 8 & 7 & 6 & 5 & 4 & 3 & 2 & 1 & 2 & 3 & 4 & 5 & 6 & 7 & 8 & 9 & $\begin{array}{c}\text { Perawatan } \\
\text { komponen }\end{array}$ \\
\hline
\end{tabular}


Tabel 2 : Nilai bobot alternatif

\begin{tabular}{|c|c|c|c|c|c|c|c|c|c|c|c|c|c|c|c|c|c|c|}
\hline Alternatif & \multicolumn{10}{|c|}{ Alternatif } \\
\hline Ignition rod & 9 & 8 & 7 & 6 & 5 & 4 & 3 & 2 & 1 & 2 & 3 & 4 & 5 & $\mathbf{6}$ & 7 & 8 & 9 & Ignition rod \\
\hline Ignition rod & 9 & 8 & 7 & 6 & 5 & 4 & 3 & 2 & 1 & 2 & 3 & 4 & 5 & 6 & 7 & 8 & 9 & Ignition rod \\
\hline Ignition rod & 9 & 8 & 7 & 6 & 5 & 4 & 3 & 2 & 1 & 2 & 3 & 4 & 5 & 6 & 7 & 8 & 9 & Ignition rod \\
\hline Ignition rod & 9 & 8 & 7 & 6 & 5 & 4 & 3 & 2 & 1 & 2 & 3 & 4 & 5 & 6 & 7 & 8 & 9 & Ignition rod \\
\hline Electroda & 9 & 8 & 7 & 6 & 5 & 4 & 3 & 2 & 1 & 2 & 3 & 4 & 5 & 6 & 7 & 8 & 9 & Electroda \\
\hline Electroda & 9 & 8 & 7 & 6 & 5 & 4 & 3 & 2 & 1 & 2 & 3 & 4 & 5 & 6 & 7 & 8 & 9 & Electroda \\
\hline Electroda & 9 & 8 & 7 & 6 & 5 & 4 & 3 & 2 & 1 & 2 & 3 & 4 & 5 & 6 & 7 & 8 & 9 & Electroda \\
\hline Nozzle tip & 9 & 8 & 7 & 6 & 5 & 4 & 3 & 2 & 1 & 2 & 3 & 4 & 5 & 6 & 7 & 8 & 9 & Nozzle tip \\
\hline Nozzle tip & 9 & 8 & 7 & 6 & 5 & 4 & 3 & 2 & 1 & 2 & 3 & 4 & 5 & 6 & 7 & 8 & 9 & Nozzle tip \\
\hline Nozzle pipe & 9 & 8 & 7 & 6 & 5 & 4 & 3 & 2 & 1 & 2 & 3 & 4 & 5 & 6 & 7 & 8 & 9 & Nozzle pipe \\
\hline
\end{tabular}

Tabel 3 : Hasil seluruh bobot

\begin{tabular}{|c|c|c|c|c|}
\hline & Penyetelan & $\begin{array}{c}\text { Kondisi } \\
\text { Komponen }\end{array}$ & $\begin{array}{c}\text { Perawatan } \\
\text { Komponen }\end{array}$ & $\begin{array}{c}\text { Bobot } \\
\text { Kriteria }\end{array}$ \\
\hline Ignition rod & 0,1289 & 0,0401 & 0,1329 & 0,7554 \\
\hline Elektroda & 0,3775 & 0,5936 & 0,4684 & 0,0699 \\
\hline Nozzle tip & 0,2540 & 0,5936 & 0,2282 & 0,1777 \\
\hline Nozzle pipe & 0,1298 & 0,1317 & 0,1006 & \\
\hline Flame eye & 0,1097 & 0,0523 & 0,0690 & \\
\hline
\end{tabular}

\section{Penghitungan Kriteria}

Tabel 4.3 Perbandingan Kriteria

\begin{tabular}{|c|c|c|c|}
\hline kriteria & penyetelan & $\begin{array}{c}\text { Kondisi } \\
\text { komponen }\end{array}$ & $\begin{array}{c}\text { Perawatan } \\
\text { komponen }\end{array}$ \\
\hline penyetelan & $1 / 1$ & 6 & 8 \\
\hline $\begin{array}{c}\text { Kondisi } \\
\text { komponen }\end{array}$ & $1 / 6$ & $1 / 1$ & $1 / 5$ \\
\hline $\begin{array}{c}\text { Perawatan } \\
\text { komponen }\end{array}$ & $1 / 8$ & 5 & $1 / 1$ \\
\hline
\end{tabular}


Ubah Matrik diatas menjadi bilangan desimal

$$
\left(\begin{array}{ccc}
1,000 & 6,000 & 8,000 \\
0,1666 & 1,000 & 0,2000 \\
0,1250 & 5,000 & 1,000
\end{array}\right)
$$

○ Rumus Matrik

Baris x Kolom

jumlah dari setiap baris matriks dan nilai hasil normalisasi: jumlah baris hasil normalisas

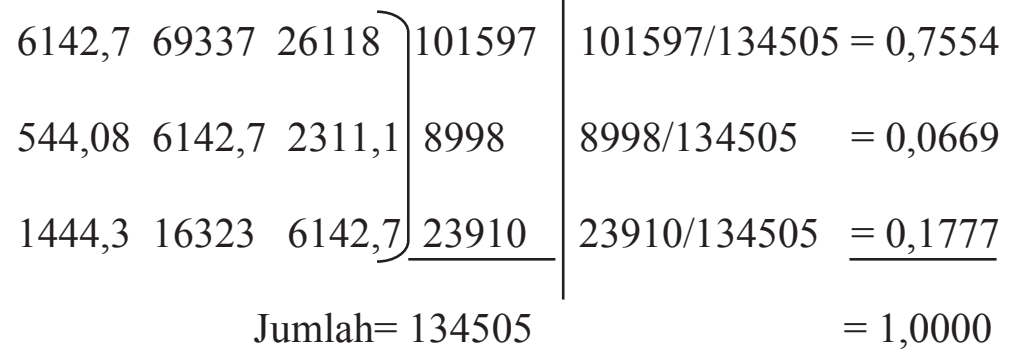

Setelah menghitung Matrik dari tiap iterasinya, dan di dapatkan sejumlah nilai eigen dari setiap iterasinya, maka akan diketahui perbandingannya. Berikut ini adalah matriks berpasangan beserta dengan nilai eigennya:

Matriks berpasangan beserta nilai eigen

\begin{tabular}{|c|c|c|c|c|}
\hline Kriteria & penyetelan & $\begin{array}{c}\text { Kondisi } \\
\text { komponen }\end{array}$ & $\begin{array}{c}\text { Perawatan } \\
\text { komponen }\end{array}$ & $\begin{array}{c}\text { Nilai } \\
\text { eigen }\end{array}$ \\
\hline Penyetelan & 1,000 & 6,000 & 8,000 & 0,7554 \\
\hline $\begin{array}{c}\text { Kondisi } \\
\text { Komponen }\end{array}$ & 0,1666 & 1,000 & 0,2000 & 0,0699 \\
\hline $\begin{array}{c}\text { Perawatan } \\
\text { Komponen }\end{array}$ & 0,1250 & 5,000 & 1,000 & 0,1777 \\
\hline
\end{tabular}

\section{Perhitungan Alternatif}

1. Perhitungan Alternatif penyetelan

$\left(\begin{array}{lllll}1,000 & 0,1666 & 0,2000 & 7,000 & 0,2000 \\ 6,000 & 1,000 & 2,000 & 7,000 & 6,000 \\ 5,000 & 0,2500 & 1,000 & 6,000 & 4,000 \\ 0,1428 & 0,1428 & 0,1666 & 1,000 & 4,000 \\ 4,000 & 0,1666 & 0,2000 & 0,2000 & 1,000\end{array}\right)$


Jumlah baris Hasil

\begin{tabular}{|c|c|c|c|c|c|c|}
\hline 5 & 1,7997 & 1,9494 & 16,4287 & 35,8 & 60,9778 & 0,1289 \\
\hline 47 & 4,5 & 8,062 & 69,5 & 49,5 & 178,562 & 0,3775 \\
\hline 28,4758 & 2,8562 & 4,3 & 49,75 & 34,75 & 120,132 & 0,2540 \\
\hline 18,1179 & 1,0174 & 1,4474 & 5 & 9,5589 & 61,4031 & 0,1298 \\
\hline 10,3570 & 1,0853 & 1,7748 & 30,8662 & 7,8 & 51,883 & 0,1097 \\
\hline & & & & & 9579 & 1,0000 \\
\hline
\end{tabular}

2. Alternatif kondisi komponen

$\left(\begin{array}{ccccc}1,000 & 0,2000 & 0,2500 & 0,2500 & 0,3333 \\ 5,000 & 1,000 & 6,000 & 6,000 & 7,000 \\ 4,000 & 0,1666 & 1,000 & 4,000 & 6,000 \\ 4,000 & 0,1666 & 0,2500 & 1,000 & 5,000 \\ 4,000 & 0,1428 & 0,1666 & 0,200 & 1,000\end{array}\right)$

jumlah dari setiap baris matriks dan nilai hasil normalisasi:

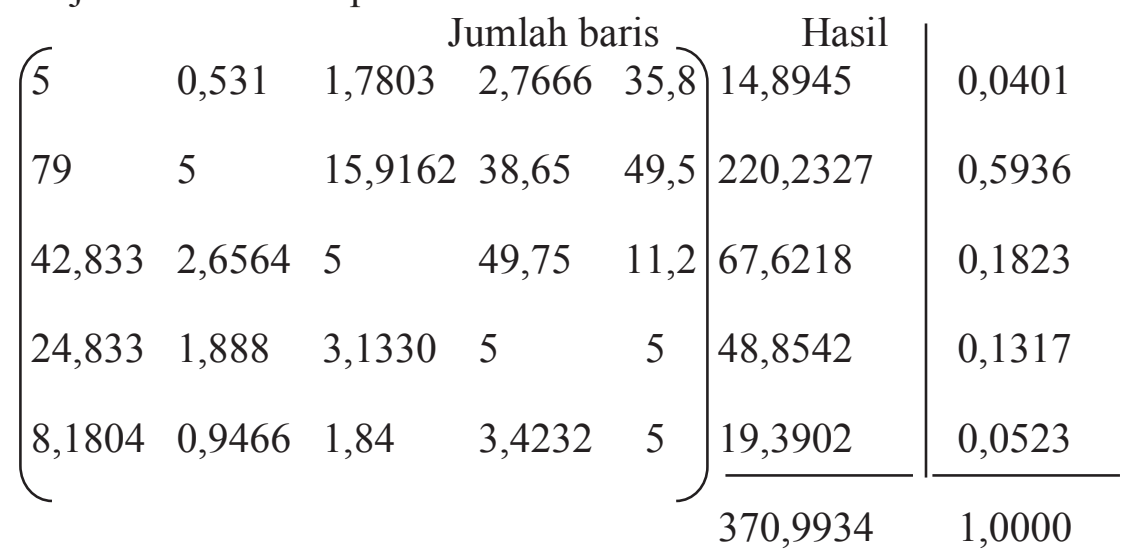

3. Perhitungan perawatan komponen

$$
\left(\begin{array}{lllll}
1,000 & 0,2000 & 0,3333 & 0,5000 & 0,3333 \\
5,000 & 1,000 & 7,000 & 5,000 & 6,000 \\
3,000 & 0,1428 & 1,000 & 5,000 & 5,000 \\
2,000 & 0,2000 & 0,2000 & 1,000 & 5,000 \\
3,000 & 0,1666 & 0,2000 & 0,2000 & 1,000
\end{array}\right)
$$


jumlah dari setiap baris matriks dan nilai hasil normalisasi:

\begin{tabular}{llllll|l|l}
\multicolumn{7}{c}{ Jumlah baris } & Hasil \\
5 & 12,029 & 2,2332 & 3,7331 & 6,0331 & 57,9715 & 0,1329 \\
59 & 5 & 17,8665 & 48,7 & 73,6665 & 204,233 & 0,4684 \\
31,714 & 2,7189 & 5 & 13,214 & 46,8568 & 99,5037 & 0,2282 \\
20,6 & 1,9189 & 3,4666 & 5 & 12,8666 & 43,8521 & 0,1006 \\
17,8333 & 1,2588 & 2,6062 & 3,7333 & 5 & 30,4316 & 0,069 \\
\hline & & & & & 435,9919 & 1,0000
\end{tabular}

Tabel Rangking Nilai Alternatif Perawatan Komponen

\begin{tabular}{|c|c|c|}
\hline Rangking & Alternatif & Nilai Eigen Perawatan Komponen \\
\hline 5 & Ignition rod & 0,1329 \\
\hline 1 & Elektroda & 0,4684 \\
\hline 2 & Nozzle tip & 0,2282 \\
\hline 4 & Nozzle pipe & 0,1006 \\
\hline 3 & Flame eye & 0,0690 \\
\hline
\end{tabular}

